\title{
Nucleolar and spindle associated protein 1 promotes the aggressiveness of astrocytoma by activating the Hedgehog signaling pathway
}

Xianqiu $\mathrm{Wu}^{1+}$, Benke $\mathrm{Xu}^{2 \dagger}$, Chao Yang ${ }^{3 \dagger}$, Wentao Wang ${ }^{4}$, Dequan Zhong ${ }^{4}$, Zhan Zhao ${ }^{4}$, Longshuang $\mathrm{He}^{4}$, Yuanjun $\mathrm{Hu}^{4}$, Lili Jiang ${ }^{5}$, Jun $\mathrm{Li}^{6}$, Libing Song ${ }^{1 *}$ and Wei Zhang ${ }^{4^{*}}$

\begin{abstract}
Background: The prognosis of human astrocytoma is poor, and the molecular alterations underlying its pathogenesis still needed to be elucidated. Nucleolar and spindle associated protein 1 (NUSAP1) was observed in several types of cancers, but its role in astrocytoma remained unknown.

Methods: The expression of NUSAP1 in astrocytoma cell lines and tissues were measured with western blotting and Real-Time PCR. Two hundred and twenty-one astrocytoma tissue samples were analyzed by immunochemistry to demonstrate the correlation between the NUSAP1 expression and clinicopathological characteristics. 3-(4,5dimethylthiazol-2-yl) 2,5-diphenyltetrazolium bromide (MTT) assay, colony formation, transwell matrix penetration assay, wound healing assay and anchorage-independent growth assay were used to investigate the biological effect of NUSAP1 in astrocytoma. An intracranial brain xenograft tumor model was used to confirm the oncogenic role of NUSAP1 in human astrocytoma. Luciferase reporter assay was used to investigate the effect of NUSAP1 on Hedgehog signaling pathway.

Results: NUSAP1 was markedly overexpressed in astrocytoma cell lines and tissues compared with normal astrocytes and brain tissues. NUSAP1 was found to be overexpressed in 152 of 221 (68.78\%) astrocytoma tissues, and was significantly correlated to poor survival. Further, ectopic expression or knockdown of NUSAP1 significantly promoted or inhibited, respectively, the invasive ability of astrocytoma cells. Moreover, intracranial xenografts of astrocytoma cells engineered to express NUSAP1 were highly invasive compared with the parental cells. With regard to its molecular mechanism, upregulation of NUSAP1 in astrocytoma cells promoted the nuclear translocation of GLI family zinc finger 1 (GLI1) and upregulated the downstream genes of the Hedgehog pathway.

Conclusion: These findings indicate that NUSAP1 contributes to the progression of astrocytoma by enhancing tumor cell invasiveness via activation of the Hedgehog signaling pathway, and that NUSAP1 might be a potential prognostic biomarker as well as a target in astrocytoma.
\end{abstract}

Keywords: Astrocytoma, NUSAP1, GLI1, Aggressiveness, Hedgehog pathway

\footnotetext{
*Correspondence: songlb@sysucc.org.cn; zw@gdpu.edu.cn

${ }^{\dagger}$ Equal contributors

${ }^{1}$ State Key Laboratory of Oncology in Southern China and Department of Experimental Research, Sun Yat-sen University Cancer Center, Guangzhou 510060, China

${ }^{4}$ Neurosurgical Research Institute, the First Affiliated Hospital of Guangdong

Pharmaceutics University, Guangzhou 510060, China

Full list of author information is available at the end of the article
} 


\section{Background}

Glioma is the most common primary brain tumor in adults, and it is also one of the most fatal human cancers. Despite various improvements in cancer treatment over the last two decades, the outcome of patients with malignant glioma remain very poor [1-3]. It has been reported that the cumulative 1 -year survival rate of glioma patient is no more than $30 \%$; moreover, the overall median survival for glioblastoma, the most lethal brain tumor, ranges from 1.4 to 1.8 years, with only a third of patients surviving for 1 year and less than 5\% surviving beyond 5 years $[4,5]$. One of the reasons why patients with glioma have such a low survival rate is that glioma tumor cells have a high degree of invasiveness [6-8].

The World Health Organization (WHO) classifies gliomas according to the cells that the tumor cells morphologically resemble (astrocytes, oligodendrocytes, or a mixture of both cell types) and groups the tumors into four grades based on histological features and aggressiveness [9]. Astrocytoma, including glioblastoma, which is the most common primary tumor type of human glioma, accounts for $75 \%$ of all gliomas [10]. The clinical prognosis of astrocytoma is still mainly dependent on conventional pathological parameters, such as the histological type and tumor grade. Even though the WHO histopathological classification is widely used, it is limited by substantial interobserver variability and poor correlation with the clinical outcomes. The progression of astrocytoma is related to various molecular alterations, but these molecular mechanisms have not been adequately elucidated. Therefore, clarifying the molecular mechanisms of astrocytoma and identifying prognostic factors as well as potential targets would have great clinical value.

Hedgehog $(\mathrm{HH})$, which was first identified in Drosophila melanogaster in the 1980s, plays a critical role in early embryonic development [11]. It has three vertebrate homologs that function as ligands: Sonic hedgehog $(\mathrm{SHH})$, Indian hedgehog $(\mathrm{IHH})$ and desert hedgehog (DHH) [12]. Smoothened (SMO), a 7-transmembrane protein related to the $\mathrm{G}$ protein-coupled receptor, and glioma-associated oncogene (GLI) are the two major $\mathrm{HH}$ signal transducers. There are three GLI proteins in vertebrates: GLI1, GLI2, and GLI3. In brief, $\mathrm{HH}$ ligands bind to Patched (PTCH1) and lead to the release of SMO into the primary cilia, which in turn results in dissociation of the suppressor-of-fused (SUFU)-GLI complex. The dissociation of this complex leads to the nuclear translocation and activation of GLI1 and GLI2, as well as the degradation of GLI3 [13]. GLI1 can also reinforce GLI activity via a positive feedback mechanism [14]. Recent evidence has shown that the $\mathrm{HH}$ pathway plays an important role in a broad range of tumors, for example, basal cell carcinoma $[15,16]$, small cell lung cancer [17], prostate cancer [18], gastric cancer [19], esophageal cancer [20], pancreatic cancer [19, 21], and hepatocellular carcinoma [22, 23]. It was reported that up to $30 \%$ of medulloblastomas (a primitive neuroectodermal tumor) exhibit activation of the $\mathrm{HH}$ pathway [24-26]. The HH pathway has been reported to be hyper-activated in multiple human tumors, including gliomas [27-30]. For instance, the expression of PTCH1, the $\mathrm{HH}$ receptor, is significant higher in grade II/III gliomas and sonic hedgehog, one of the $\mathrm{HH}$ ligands, overexpresses in $80 \%$ of the human glioblastoma multiforme (GBM) [27, 28]. Further studies showed that $66.7 \%$ primary and recurrent gliomas showed Gli1nuclear expression, which positively correlated with glioma progression $[29,30]$. However, $\mathrm{HH}$ pathway driver mutations are thought to be of low frequency in gliomas, suggesting that alternative mechanism is involved in activation of $\mathrm{HH}$ pathway in gliomas.

Nucleolar spindle-associated protein 1 (NUSAP1) is a microtubule-associated protein that plays an important role in spindle assembly, chromosome segregation, cytokinesis, and microtubule crosslinking, bundling and attachment to chromosomes [31, 32]. NUSAP1 was identified as a microtubule stabilizer as a result of its ability to induce microtubule crosslinking, bundling, and attachment to chromosomes [33, 34]. High expression of NUSAP1 has been observed in several types of tumors, such as pancreatic adenocarcinoma, acute myeloid leukemia and prostate cancer [35-38]. However, although a number of studies have explored the role of NUSAP1 in various tumors, its role in astrocytoma remains unknown.

In an effort to understand the role of NUSAP1 in astrocytoma, the present study investigates the expression of NUSAP1 in astrocytoma cell lines and tissues. Our findings indicated that NUSAP1 played an important role in promoting aggressiveness in astrocytoma via activating the $\mathrm{HH}$ pathway. Thus, NUSAP1 might be a useful prognostic biomarker and a potential target in the diagnosis and treatment of astrocytoma.

\section{Methods \\ Cell lines}

Primary normal human astrocytes (NHAs) were purchased from Sciencell Research Laboratories. The glioma cell lines U-118MG, U-87MG, A-172, SW 1088, SW 1788 and LN-18 were purchased from American Type Culture Collection (ATCC). These cells were grown in Dulbecco's modified Eagle medium (DMEM) supplemented with $10 \%$ fetal bovine serum (FBS). U138MG was also purchased from ATCC and cultured in DMEM supplemented with 10\% FBS. Fresh brain tumor tissues that were clinically histopathologically diagnosed at the Sun Yat-sen University-Affiliated First Hospital were used. Patient's consent and approval from the 
Institutional Research Ethics Committee were acquired for use of data for the research. All the tissues were collected and processed within $30 \mathrm{~min}$ after resection. The primary cultured tumor cells were obtained after mechanical dissociation, as previously described [39].

\section{Patient information and tissue specimens}

A total of 221 paraffin-embedded glioma samples, including WHO grade II-IV tumors, were used in this study. All of them were both clinically and pathologically diagnosed at the Sun Yat-sen University-Affiliated First Hospital between 2000 and 2010. The clinicopathological characteristics of the specimens are shown in Additional file 1: Table S1. Normal brain tissues were obtained from individuals who had died from traffic accidents and confirmed to be free of any preexisting pathologically detectable conditions. Prior donor consent and the approval of the Institutional Research Ethics Committee were obtained for use of the data. Clinical and pathological classification was conducted according to the seventh edition of the classification system of the American Joint Committee on Cancer (AJCC).

\section{RNA extraction, reverse transcription and real-time RT-PCR} Total RNA was extracted from cell lines and freshly frozen samples with TRIzol reagent (Invitrogen, Carlsbad, CA, USA) and was reverse-transcribed with the firststrand cDNA synthesis kit (Invitrogen). Real-time PCR reactions were conducted using Platinum SYBR Green qPCR SuperMix-UDG reagents (Invitrogen). Reverse transcriptase was used as the negative control, and glyceraldehyde-3-phosphate dehydrogenase (GAPDH) was used as the endogenous control. All experiments were repeated twice. The $2^{-\Delta \Delta C T}$ equation was used to calculate the relative expression levels. The PCR primers used in this study were as follows: NUSAP1 (5': GAAGCGCGGCATTCTTCATT, 3': CGGCGATACT CGGAAGATGG), GAPDH (5': CACCATCTTCCAGG AGCGAG, 3': GACTCCACGACGTACTCAGC), GLI1 (5': GCTCTGGACATACCCCACCT,3': GCAGCTCCC CCAATTTTTCTG), PTCH1 (5': TCGCTCTGGAGCAGATTTCC, 3': TCTCGAGGTTCGCTGCTTTT), HIP1 (5': GGCGACATGGATCGGATGG, 3': ACAGCCACT TCCTGCGTATT), CCND1 (5': AAAGAATTTGCACC CCGCTG, 3': GACAGACAAAGCGTCCCTCA), CC NE1 (5', GCAGGATCCAGATGAAGAAATG, 3': TAA TCCGAGGCTTGCACGTT), HDAC1 (5': TGCAAA GAAGTCCGAGGCAT, 3': ACCCTCTGGTGATACT TTAGCA).

\section{Vectors, retroviral infection and transfection}

PMSCV/NUSAP1 was generated by subcloning the PCRamplified human NUSAP1 coding sequence into the pMSCV vector (Clontech). Human NUSAP1 targeting
shRNA oligonucleotide sequences (RNA\#1: 5GCACCAAGAAGCTGAGAATGC-3, and RNA\#2: 5'GGAAATGGAGTCCATTGATCA-3) were cloned to generate pSuperretro-NUSAP1-shRNA(s). The Lipofectamine 3000 reagent (Invitrogen) was used for transfecting plasmids. Retroviral production and infection were performed as described previously [40]. Stable cell lines expressing NUSAP1 or NUSAP1 shRNA were selected for 10 days by treatment with $0.5 \mu \mathrm{g} / \mathrm{ml}$ puromycin for $48 \mathrm{~h}$ after infection. In the same way, stable cell lines expressing Nusap1 shRNA (RNAi\#1, 5-GCATGTTAAGGAAAC TCAGCC-3, and RNAi\#2, 5-GCAGCGCCTCATCAA GAAAGT-3) were established and selected. Human GLI1 targeting shRNA oligonucleotides sequences were as follows: RNA\#1: 5-GCCACCAAGCTAACCTCATGT-3, and RNA\#2: 5-GCCTGAATCTGTGTATGAAAC-3.

\section{Western blot analysis}

Western blot analysis was conducted using antiNUSAP1, anti-GAPDH, anti- $\alpha$-tubulin, anti-MMP2, anti-MMP9, anti-Ki67, anti- $\beta$-actin, and anti-elongation factor 1 alpha $(E F 1 \alpha)$ antibodies (Abcam, Cambridge, MA, USA). Human GAPDH, $\alpha$-tubulin, $\beta$-actin, or EF1$\alpha$ were used as the endogenous reference.

\section{Immunohistochemistry}

Immunohistochemistry was performed in 221 clinical glioma tissue sections using a previously described method [41]. The degree of immunostaining was reviewed and scored separately by two independent pathologists blindly. The scores were determined by combining the proportion of positively-stained tumor or normal pancreatic epithelial cells and the intensity of staining. Cell proportions were scored as follows: 0, no positive cells; $1,<10 \%$ positive cells; $2,10 \%-35 \%$ positive cells; $3,35 \%-75 \%$ positive cells; $4,>75 \%$ positive cells. Staining intensity was graded according to the following standard: 1, no staining; 2, weak staining (light yellow); 3 , moderate staining (yellow brown); 4, strong staining (brown). The staining index (SI) was calculated as the product of the staining intensity score and the proportion of positive cells. Using this method of assessment, we evaluated protein expression of NUSAP1 in glioma specimens by determining the SI, with possible scores of $0,2,3,4,6,8,9,12$, and 16 . Sample with a score index $\geq 8$ were determined as high expression and samples with a score index $<8$ were determined as low expression.

\section{MTT assay}

Cells $\left(5 \times 10^{3}\right.$ per well $)$ were seeded in 96-well culture plates and stained with $100 \mu \mathrm{l}$ of sterile MTT dye (0.5 mg/ml; Sigma, St. Louis, Missouri, USA) at 1, 2, 3, 4 and 5 days; this was followed by additional incubation 
for $4 \mathrm{~h}$ at $37{ }^{\circ} \mathrm{C}$. After removal of the culture medium from each well, $150 \mu \mathrm{l}$ of dimethyl sulfoxide (Sigma, St. Louis, MO, USA) was added and thoroughly mixed for 15 min. Following this, a microplate reader (Bio-Rad 3500; Hercules, California, USA) was used to determine the optical density, and absorbance was measured at a wavelength of $570 \mathrm{~nm}$ with a reference wavelength of $655 \mathrm{~nm}$. All the experiments were repeated three times.

\section{Colony formation}

The indicated cells were plated in 6 -well plates $\left(1 \times 10^{3}\right.$ cells per well) and cultured for 2 weeks. The colonies were fixed with methanol for $10 \mathrm{~min}$ and stained with $1 \%$ crystal violet for $1 \mathrm{~min}$. All the experiments were repeated three times.

\section{Transwell migration assay and Transwell matrix penetration assay}

For the Transwell assay or Transwell matrix penetration assay, the indicated cells $\left(1 \times 10^{4}\right)$ were plated on the upper side of a polycarbonate Transwell filter with or without Matrigel in the upper chamber of the BioCoat ${ }^{\mathrm{mm}}$ invasion chambers (BD, Bedford, MA). After $22 \mathrm{~h}$ of incubation at $37{ }^{\circ} \mathrm{C}$, the cells in the upper chamber were removed with cotton swabs, and the migrated and invaded cells on the lower membrane surface were fixed in $1 \%$ paraformaldehyde and stained with hematoxylin. The cells were counted (ten random 100x fields per well) and expressed as the mean number of cells per field of view. All the experiments were repeated three times, and the data were expressed as mean \pm standard deviation (SD) values.

\section{Wound healing assay}

The indicated cells were cultured on 6-well plates with DMEM containing 10\% FBS. Until the cells become confluence, we made a $500-\mu \mathrm{m}$ wide cell-free gap by scratching the bottom of the plate with a pipette tip, and the cells were further incubated for $24 \mathrm{~h}$. Phase-contrast images of the wound healing process were obtained digitally using an inverted Olympus IX50 microscope with a $10 \times$ objective lens at 0 and $24 \mathrm{~h}$ after the scratching. Then, the length of the healed wound was compared with the length of the initial wound.

\section{Anchorage-independent growth assay}

The indicated cells were trypsinized and suspended in complete medium containing $0.3 \%$ agar. The cell-agar mixture was plated on the top of a bottom layer with $1 \%$ agar-containing medium. About 10 days later, viable colonies that were larger than $0.5 \mathrm{~mm}$ in diameter were counted. All the experiments were repeated three times.

\section{Luciferase assay}

The indicated cells were co-transfected with the indicated plasmids and luciferase reporter plasmids in 6-well plates and culture for $48 \mathrm{~h}$, after which the cells were harvested and lysed for luminescence detection. The procedure and detection were performed with a luciferase assay kit according to the manufacturer's protocol. Renilla luciferase was activated for emission of primary luminescence. All the experiments were repeated three times.

\section{Intracranial brain tumor xenografts, immunohistochemistry, and hematoxylin-eosin staining} The animal studies were approved by the Ethics Committee of Sun Yat-Sen University, and all the experiments conform to the relevant regulatory standards. SW 1088 cells $\left(5 \times 10^{5}\right)$, SW 1088/NUSAP1 cells $\left(5 \times 10^{5}\right)$, U-87 MG/Scramble cells $\left(5 \times 10^{5}\right)$, or U-87 MG/ NUSAP1 shRNA\#1 cells $\left(5 \times 10^{5}\right)$ were stereotactically implanted into the brain of nude mice (five mice per group). The tumor-bearing mice were sacrificed 5 weeks after implantation, and the whole brain was resected. The brain specimens were cut to about $4-\mu \mathrm{m}$ sections and embedded in paraffin for immunohistochemistry and hematoxylin-eosin (H\&E) staining. After deparaffinization, immunohistochemistry was conducted using an anti-NUSAP1 antibody. Deparaffinized tumor sections were stained with Mayer's hematoxylin solution for H\&E staining. Images were captured using the AxioVision Rel.4.6 computerized image analysis system (Carl Zeiss).

\section{Statistical analysis}

All statistical analyses were carried out with SPSS v13.0 (SPSS Inc., Chicago, IL, USA). The relationship between NUSAP1 expression and clinicopathological characteristics was analyzed by the chi-square test. Bivariate correlations between study variables were determined using Spearman's rank correlation coefficients. Survival curves were plotted using the Kaplan-Meier method and the log-rank test. Survival data were evaluated using univariate and multivariate Cox regression analyses. $P$ values less than 0.05 were considered to indicate statistical significance.

\section{Results \\ Upregulation of NUSAP1 in astrocytoma cell lines and tissues}

We first analyzed the expression levels of NUSAP1 in astrocytoma, including anaplastic astrocytoma $(n=19)$ and glioblastoma $(n=81)$, using data deposited in the Oncomine database. NUSAP1 expression was found to be upregulated in astrocytoma compared to normal brain tissues (Fig. 1a). Further, analysis of NUSAP1 expression from data deposited in The Cancer Genome 


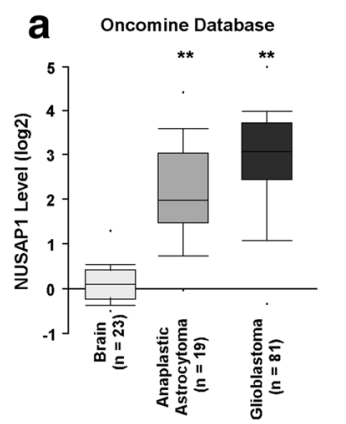

d

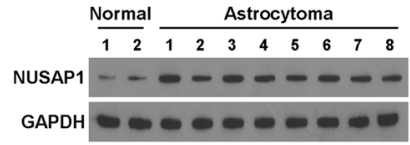

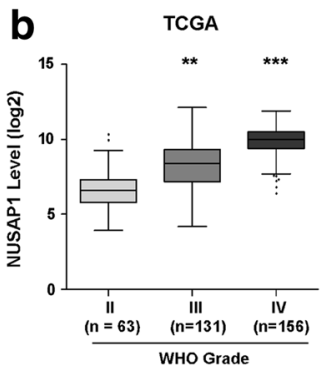

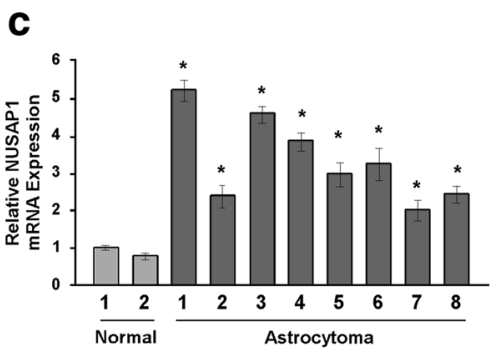

$\mathbf{f}$

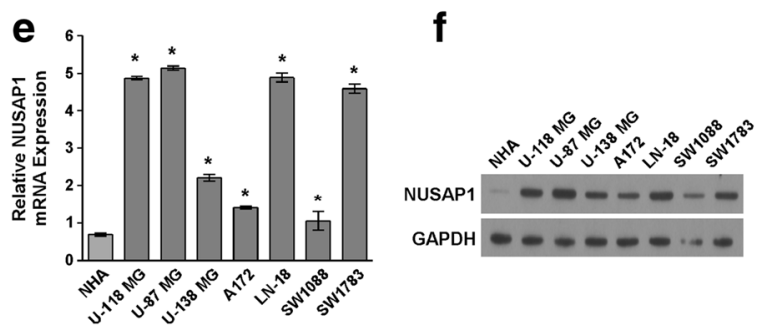

Fig. 1 Upregulation of NUSAP1 expression in astrocytoma cell lines and tissues. a Based on data obtained from the Oncomine database, the expression of NUSAP1 was markedly upregulated in anaplastic astrocytoma $(n=19)$ and glioblastoma $(n=81)$ compared with normal brain tissues $(n=23)$. Error bars represent the mean \pm SD values $\left({ }^{*} P<0.05\right)$. b NUSAP1 expression was upregulated in grade IV astrocytoma $(n=156)$, followed by grade III astrocytoma $(n=131)$ and grade II astrocytoma $(n=63)$, according to The Cancer Genome Atlas (TCGA) database. Error bars represent the mean values determined using the Tukey test (**P<0.05). $\mathbf{c}$ and $\mathbf{d}$ Real-time RT-PCR and western blotting analysis of NUSAP1 expression in astrocytoma tissue and brain tissue. The average NUSAP1 mRNA expression was normalized to the expression of GAPDH. GAPDH was used as a loading control. Error bars represented the mean \pm SD values of three independent experiments $\left({ }^{*} P<0.05\right)$. e and $\mathbf{f}$ Expression of NUSAP1 was upregulated in all seven astrocytoma cell lines compared with primary normal human astrocytes (NHAs), as confirmed by RT-PCR and western blotting analyses. GAPDH was used as a loading control. Error bars represent the mean \pm SD values of three independent experiments $\left({ }^{*} P<0.05\right)$

Atlas (TCGA) database revealed that the increase in the mRNA expression of NUSAP1 in astrocytoma tissues was in tandem with the increase in the WHO grade of the tumor (Fig. 1b). To further confirm these results obtained from public datasets, we examined the expression of NUSAP1 in two normal brain tissues, eight astrocytoma tissues, one primary normal human astrocyte (NHA) cell line and seven astrocytoma cell lines by realtime PCR and western blotting. Real-time PCR and western blotting analyses revealed that the mRNA and protein expression of NUSAP1 was higher in the eight astrocytoma tissues than in the two normal brain tissues (Fig. 1c and d). Compared with the NHA cell line, the expression of NUSAP1 was also upregulated in all seven astrocytoma cell lines, as confirmed by RT-PCR analyses and western blotting (Fig. 1e and f). Thus, our data indicated that the expression of NUSAP1 was upregulated in astrocytoma cell lines and tissues.

\section{NUSAP1 overexpression correlated with poor survival in patients with astrocytoma}

As the expression of NUSAP1 was upregulated in astrocytoma, we further investigated whether there was a correlation between NUSAP1 expression and survival. We analyzed the expression of NUSAP1 in astrocytoma samples which were selected from low grade glioma
(LGG) data of the TCGA databases to perform the survival analysis and found that astrocytoma patients with high NUSAP1 expression had poorer overall survival than patients with low NUSAP1 expression (Fig. 2a). Moreover, upregulation of NUSAP1 was closely related to shorter relapse-free survival (Fig. 2b). To investigate the association between NUSAP1 and clinical characteristics of the patients, we examined NUSAP1 expression by immunohistochemical analysis of 221 paraffin-embedded astrocytoma tissues (Additional file 1: Table S1). Among the NUSAP1-positive cases, 69 (31.22\%) had low NUSAP1 expression, while 152 (68.78\%) had high NUSAP1 expression (Additional file 1: Table S1). Furthermore, NUSAP1 expression increased markedly with human glioma WHO grade and quantitative IHC analysis revealed that the mean optical density (MOD) of NUSAP1 staining in glioma cells increased significantly with the WHO grade, consistently (Fig. 2, C-E), suggesting that high NUSAP1 protein expression contributes to glioma progression.

Moreover, the statistical analysis indicated that upregulated NUSAP1 protein was associated with WHO tumor grade $(P<0.001)$ and vital status $(P<0.001)$ (Additional file 1: Table S2). Kaplan-Meier analysis and log-rank testing revealed that NUSAP1 expression levels were inversely correlated with survival time, whether at 

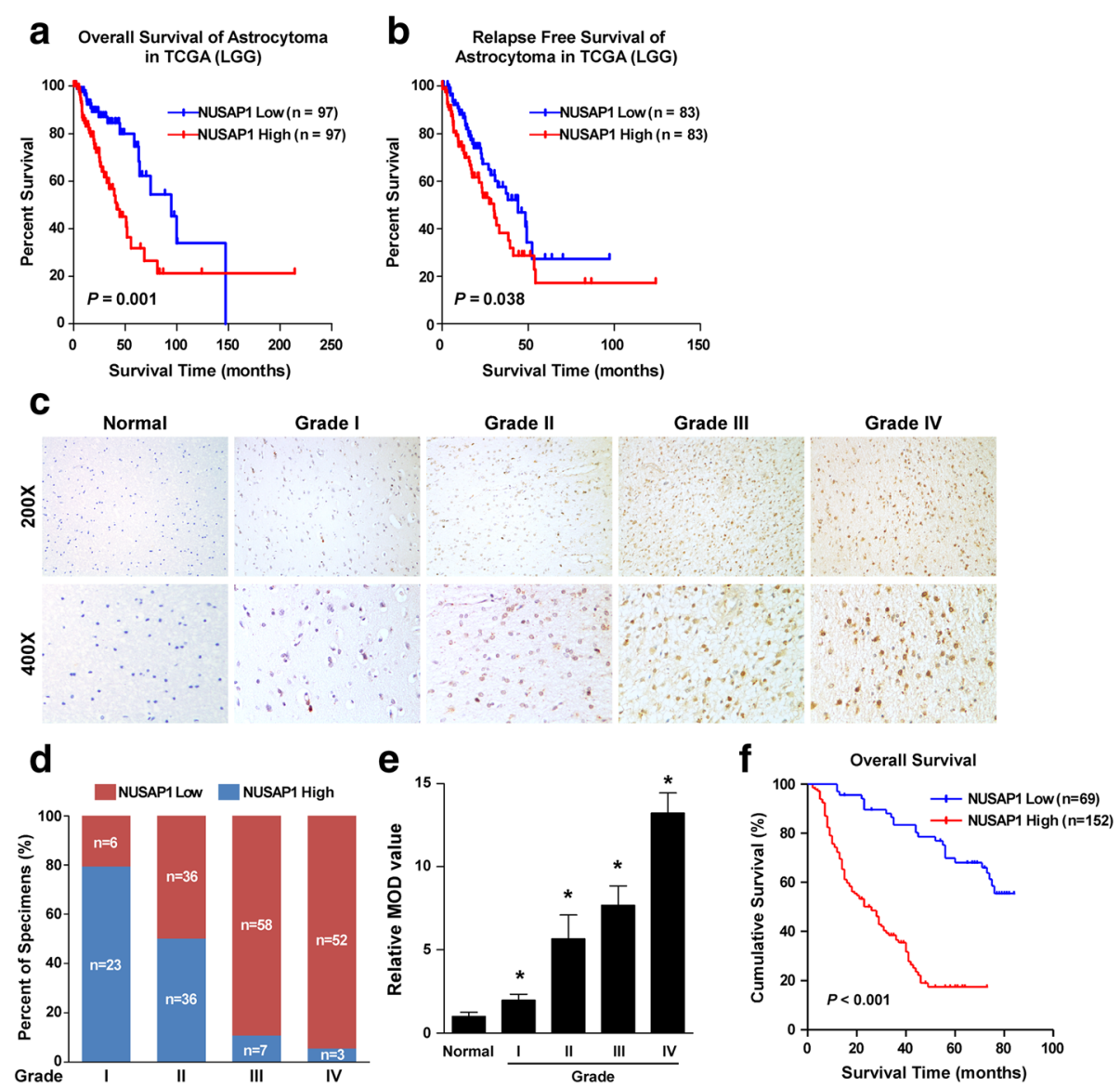

Fig. 2 Association of NUSAP1 upregulation with poor survival in astrocytoma. (A and B) Kaplan-Meier overall survival and relapse-free survival curves for patients with astrocytoma (selected from LGG data of TCGA database) stratified by high and low expression of NUSAP1. c Representative images of NUSAP1 expression in astrocytoma of different grade. $\mathbf{d}$ Immunohistochemical analysis of astrocytoma tissue samples of different grades according to the level of NUSAP1 expression. e Statistical quantification of the average MODs of NUSAP1 staining of glioma specimens with different WHO grades. $\mathbf{f}$ Kaplan-Meier overall survival curves for patients with astrocytoma stratified by low $(n=69)$ and high $(n=152)$ expression of NUSAP1 $\left.(P<0.001) .{ }^{*}, P<0.05\right)$

WHO grade I-II or at WHO grade III-IV (Fig. 2F; Additional file 2: Figure S1). Moreover, univariate and multivariate survival analyses revealed that NUSAP1 expression was an independent prognostic factor of glioma $(P<0.001)$ similar to the WHO grade $(P<0.001)$ (Additional file 1: Table S3). Taken together, NUSAP1 protein upregulation in glioma contributes to glioma progression and correlates with poor prognosis of the disease.

\section{Upregulation of NUSAP1 augmented the aggressiveness of astrocytoma in vitro}

To investigate whether NUSAP1 has an effect on the pathogenesis of astrocytoma, we used gene set enrichment analysis (GSEA) to predict the possible biological functions of NUSAP1 in the cancer. The findings indicated that NUSAP1 might be involved in proliferation of the cancer cells (Fig. 3a). To verify this, several stable cell lines were established: the SW 1008 and A172 cells stably expressed ectopic NUSAP1, while NUSAP1 expression was silenced in the U-87 MG and A172 cells by small hairpin RNA (shRNA) (NUSAP1 expression was confirmed in these cell lines by western blotting) (Fig. 3b and Additional file 3: Figure S2A). The effect of NUSAP1 on proliferation of astrocytoma cells was evaluated by overexpression and silencing of NUSAP1 transcripts. The 3-(4, 5-dimethyl-2-thiazolyl)-2,5-diphenyl-2H-tetrazolium bromide (MTT) assay showed that the NUSAP1-transduced astrocytoma cells (SW 1088 and A172 cells) displayed a significant increase in viability, while the NUSAP1-silenced U-87 MG and A172 cells displayed contrasting results (Fig. 3c and Additional file 3: Figure S2B). These results were further confirmed by the colony formation assay (Fig. 3d and Additional file 3: Figure S2C). Furthermore, in the Transwell matrix penetration assay, overexpression of NUSAP1 was found to enhance invasion in the SW 1088 and A172 cells, while knockdown of NUSAP1 inhibited cell invasion in the U-87 MG and A172 cells (Fig. 3e and 

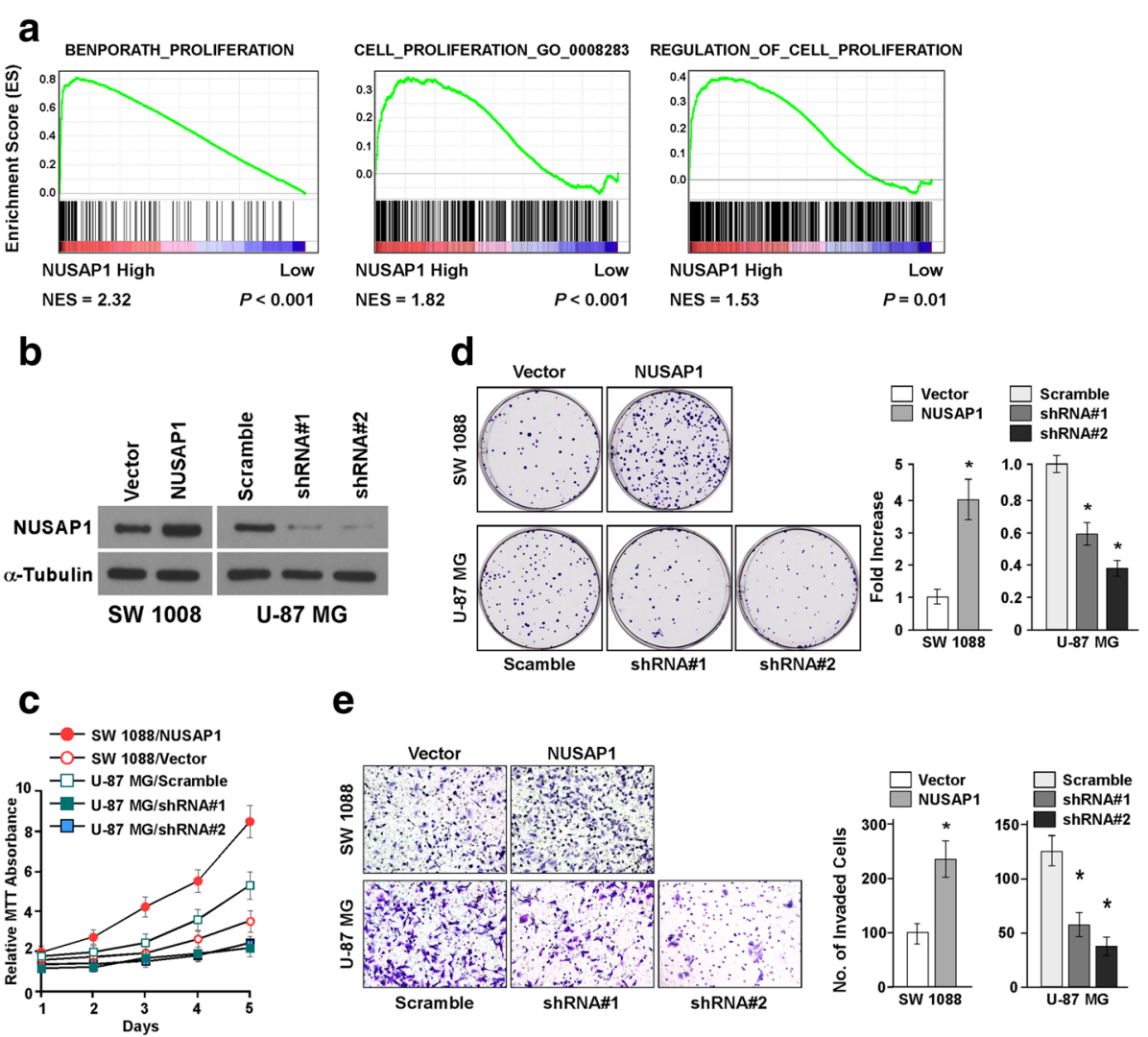

e
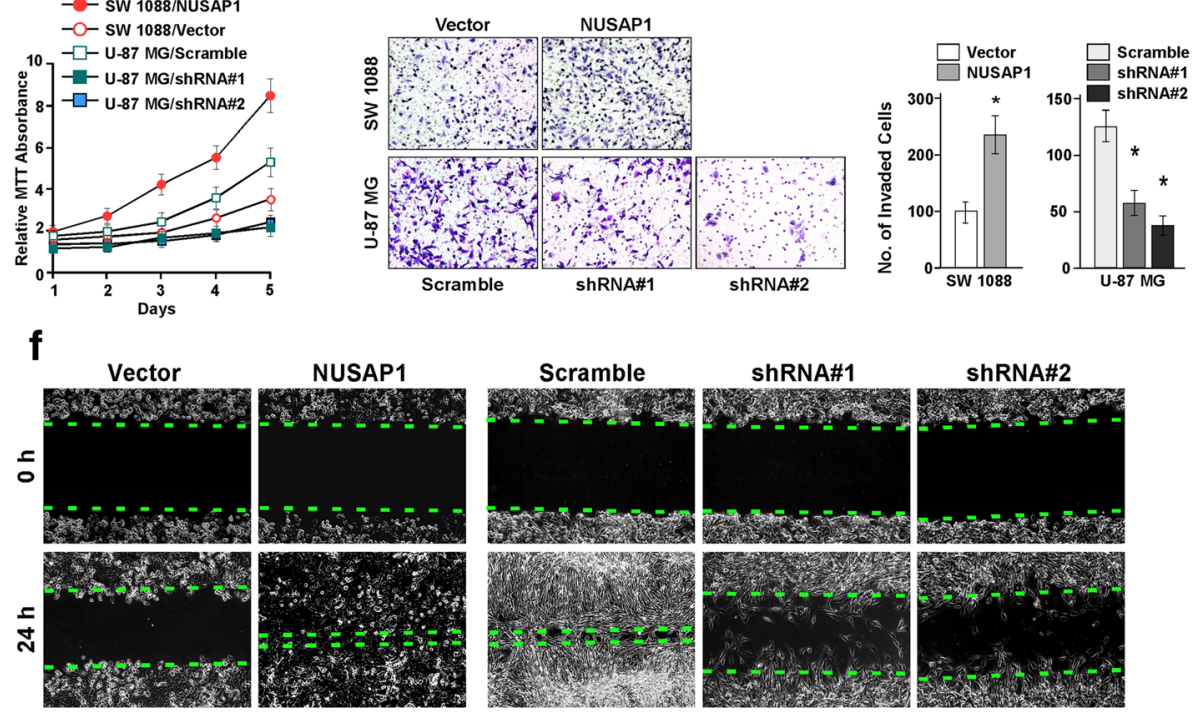

SW 1088

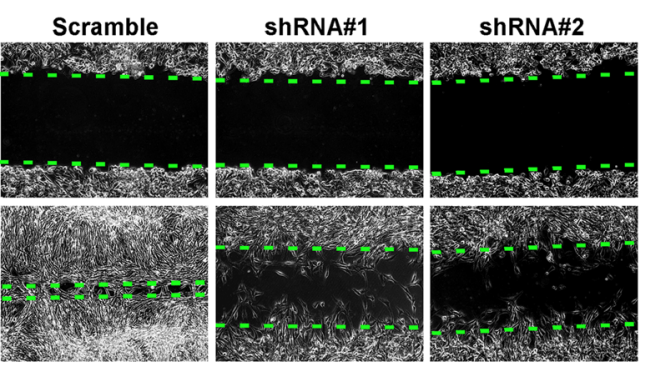

U-87 MG

Fig. 3 In vitro promotion of aggressiveness in astrocytoma by the upregulation of NUSAP1. a Gene set enrichment analysis (GSEA) showed a significant correlation between NUSAP1 mRNA expression and the proliferation-associated gene signature. $\mathbf{b}$ Western blotting was used to examine the protein expression of NUSAP1 in SW 1008 and U-87 MG cells. a-Tubulin was used as a loading control. c In the MTT assay, overexpression of NUSAP1 significantly increased the growth rate of the indicated cells, while downregulation of NUSAP1 decreased the growth rate of the indicated cells. Error bars represent the mean \pm SD values of three independent experiments. $\mathbf{d}$ Representative images (left panel) and quantification (right panel) of cells in the colony formation assay. Overexpression of NUSAP1 increased, while downregulation of NUSAP1 decreased, the colony-forming ability of the indicated cells. Error bars represent the mean \pm SD values of three independent experiments $\left({ }^{*} P<0.05\right)$. e Representative images (left panel) and quantification (right panel) of the indicated invaded cells analyzed by the Transwell matrix penetration assay. Error bars represent the mean \pm SD values of three independent experiments $\left({ }^{*} P<0.05\right)$. f The wound-healing assay was conducted with the indicated cells, and images were taken at 0 and $24 \mathrm{~h}$. Overexpression of NUSAP1 increased, while downregulation of NUSAP1 decreased, the migration ability of the indicated cells

Additional file 3: Figure S2D). We also found that the NUSAP1-transduced astrocytoma cells displayed an increase in migration ability, while the NUSAP1silenced cells displayed a decrease in their migration ability in the wound healing assay (Fig. 3f and Additional file 3: Figure S2E). These observations indicated that upregulation of NUSAP1 promoted the proliferation, invasion and migration of astrocytoma cells.

Upregulation of NUSAP1 promotes the aggressiveness of astrocytoma in vivo

As indicated by the above results, NUSAP1 promoted the aggressiveness of astrocytoma. Therefore, we tried to 
confirm whether NUSAP1 had the same effect in vivo. Before conducting the in vivo experiment, we simulated the internal environment to evaluate the growth ability of astrocytoma cells via an anchorage-independent growth assay. As demonstrated by the anchorageindependent growth assay, overexpression of NUSAP1 markedly increased the anchorage-independent growth ability of SW 1088 and A172 cells, while suppression of NUSAP1 reduced that growth ability of U-87 MG and A172 cells (Fig. 4a and Additional file 3: Figure S2F). Subsequently, the SW 1088 and U-87 MG cell lines, which stably overexpressed and suppressed NUSAP1 expression, respectively, were stereotactically implanted into the brain of nude mice; there was also a control group in which a control astrocytoma cell line was implanted. Upregulation of NUSAP1 significant shortened the survival of mice, while silencing of NUSAP1 increased the survival of mice (Fig. 4b). Immunohistochemical staining with an anti-NUSAP1 antibody showed that there was a significant increase in the positive staining densities of NUSAP1-overexpressing tumor samples as compared to the control tumor samples, while the positive staining density was decreased significantly in NUSAP1-suppressed samples (Fig. 4c). The findings also consistently showed that the tumor margins of the NUSAP1-overexpressing tumor samples were more incomplete, while the tumor margins of NUSAP1suppressed tumor specimens were more complete. Thus, the findings indicate that NUSAP1 promotes aggressiveness in astrocytoma in vivo. To understand the underlying mechanism, we examined whether NUSAP1 could alter the extracellular matrix around the tumor cells. As revealed by western blotting, MMP2, MMP9 and Ki67 showed strong expression in the NUSAP1-transduced cell line, while MMP2, MMP9 and Ki67 expression was weak in the NUSAP1-knockdown cell lines (Fig. 4d and Additional file 3: Figure S2G). Collectively, these data indicated that overexpression of NUSAP1 promoted aggressiveness in astrocytoma.

\section{Overexpression of NUSAP1 activates $\mathrm{HH}$ signaling}

Previously, Peterson KA et al. defined a prioritized set of 841 enriched Gli1-binding regions (GBRs), including NUSAP1 [42] which prompted us guess to whether there was any association between $\mathrm{HH}$ pathway and NUSAP1. Interestingly, GSEA analysis revealed that the expression level of NUSAP1 in TCGA astrocytoma dataset was positively correlated with the $\mathrm{HH}$ pathway gene signature (Fig. 5a), further suggested that NUSAP1 may play a role in activation of $\mathrm{HH}$ pathway. Furthermore, we found that upregulation of NUSAP1 resulted in an increase in the protein level of GLI1 in the nucleus,
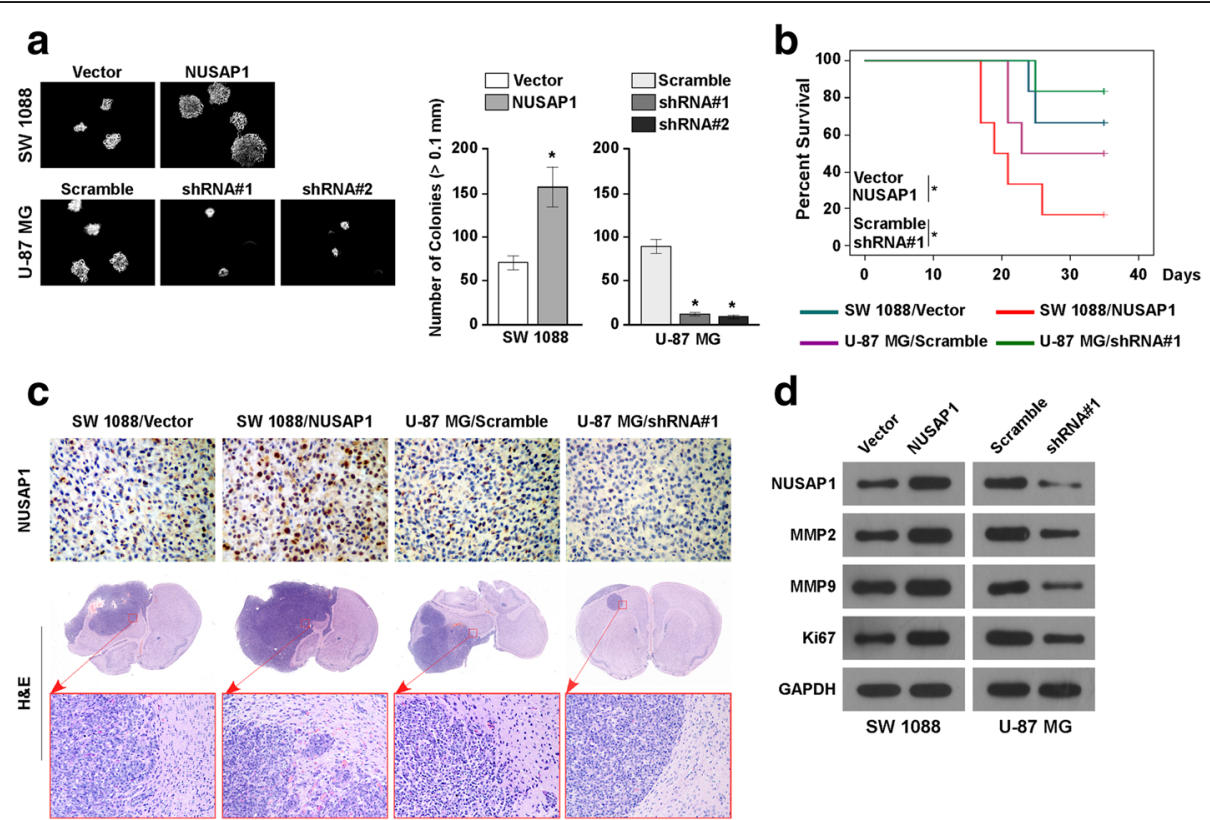

Fig. 4 In vivo promotion of the aggressiveness of astrocytomas by overexpression of NUSAP1. a Representative images (left panel) and quantification (right panel) of the indicated invaded cells by the anchorage-independent growth assay. Error bars represent the mean \pm SD values of three independent experiments $(* P<0.05)$. b Survival curves of mice with brain astrocytoma xenografts formed by the indicated cells $(* P<0.05)$. c Representative images of the tumor formed from the indicated cells in the intracranial brain tumor xenograft nude mice. Immunohistochemistry staining (upper panel) with the NUSAP1 antibody and hematoxylin-eosin staining (lower panel) demonstrated that overexpression of NUSAP1 induced, whereas downregulation of NUSAP1 inhibited, the aggressive phenotype of astrocytoma cells in vivo. $\mathbf{d}$ Western blotting was used to assess the expression of NUSAP1, MMP2, MMP9 and Ki67 in the indicated cells. GAPDH was used as a loading control 

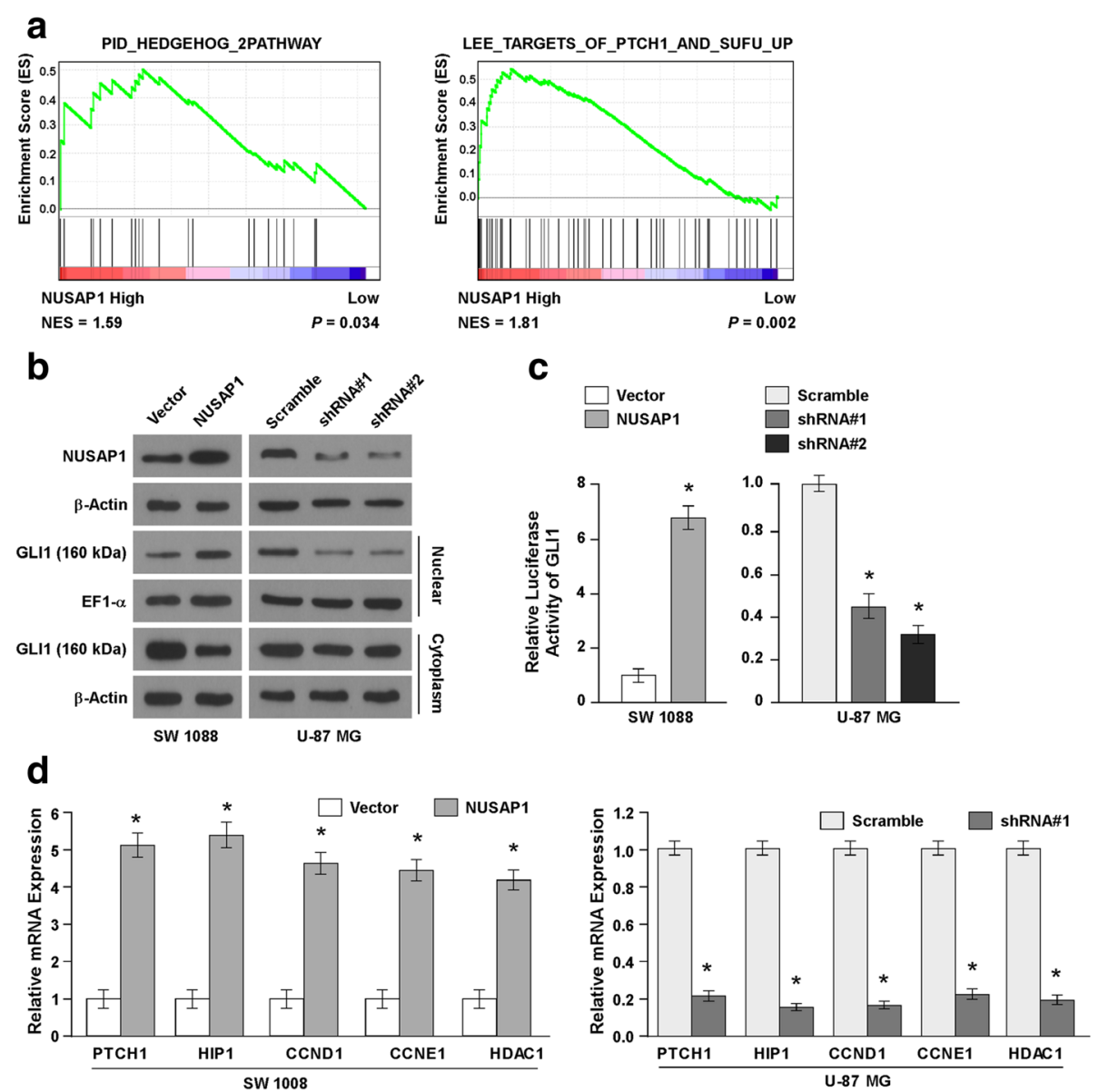

Fig. 5 Activation of Hedgehog signaling by overexpression of NUSAP1. a Gene set enrichment analysis (GSEA) showed that there was a significant correlation between NUSAP1 mRNA expression and the Hedgehog pathway gene signature. $\mathbf{b}$ Western blotting was used to examine the expression of NUSAP1 and GLI1 in the indicated cells. $\beta$-actin and EF1-a were used as loading controls. c Relative activity of reporter luciferase linked to NUSAP1 and GLI1 in the indicated cells. Error bars represent the mean \pm SD values of three independent experiments $(* P<0.05)$. $\mathbf{d}$ real-time-PCR detection of PTCH1, HIP1, CCND1, CCNE1 and HDAC1 gene expression in SW 1008 and U-87 MG cells. Error bars represent the mean \pm SD values of three independent experiments $\left({ }^{*} P<0.05\right)$

while the protein level of GLI1 in cytoplasm was decreased (Fig. 5b and Additional file 4: Figure S3A). Further, downregulation of NUSAP1 could decrease the protein level of GLI1 in the nucleus, while slightly altering GLI1 expression in the cytoplasm. Consistent with the results of western blotting, the Luciferase reporter assays showed that the activity of GLI1 was upregulated in NUSAP1-transduced cells and downregulated in NUSAP1-knockdown cells (Fig. 5c and Additional file 4: Figure S3B). Subsequently, we detected several target genes downstream of the $\mathrm{HH}$ signaling pathway by realtime PCR, including PTCH1, HIP1, CCND1, CCNE1 and HDAC1 (Fig. 5d and Additional file 4: Figure S3CD). Upregulation of NUSAP1 increased, while downregulation NUSAP1 decreased, the expression of PTCH1, HIP1, CCND1, CCNE1 and HDAC1. Our data indicated that NUSAP1 promoted GLI1 translocation to the nucleus from the cytoplasm and subsequently led to activation of the $\mathrm{HH}$ signaling pathway in astrocytoma cells.

\section{Promotion of tumor aggressiveness by overexpression of NUSAP1 via activation of $\mathrm{HH}$ signaling}

To confirm whether NUSAP1 promotes tumor aggressiveness by activating the $\mathrm{HH}$ pathway, we induced knockdown of the expression of GLI1 by small interfering RNA in NUSAP1-transduced SW1008 cells. As confirmed by RT-PCR, the mRNA level of GLI1 was significantly decreased in NUSAP1-siGLI1 cells (Fig. 6a). Further, the colony formation assay showed that the colony-forming ability of NUSAP1-siGLI1 cells was decreased in comparison with NUSAP1-transduced SW 1088 cells. When the NUSAP1-tranduced SW 1088 cells were treated with GANT61-a small-molecule inhibitor 

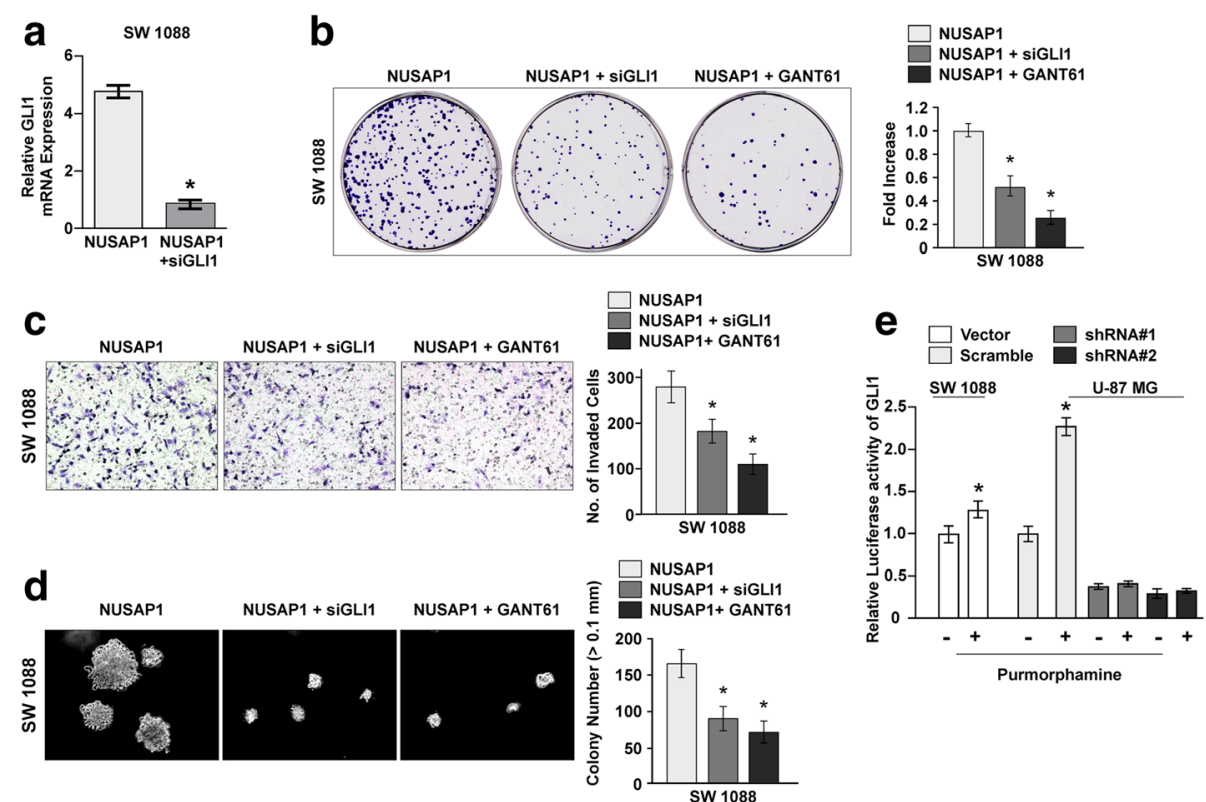

Fig. 6 Promotion of tumor aggressiveness by NUSAP1 overexpression via activation of Hedgehog signaling. a RT-PCR detection of GLI1 expression in the indicated cells. Error bars represent the mean \pm SD values of three independent experiments $(* P<0.05)$. b Representative images (left panel) and quantification (right panel) of the indicated cells in the colony formation assay. Error bars represent the mean \pm SD values of three independent experiments ( $\left.{ }^{*} P<0.05\right)$. c Representative images (left panel) and quantification (right panel) of the indicated invaded cells analyzed by the Transwell matrix penetration assay. Error bars represent the mean \pm SD values of three independent experiments $\left({ }^{*} P<0.05\right)$. $\mathbf{d}$ Representative images (left panel) and quantification (right panel) of the indicated invaded cells analyzed by the anchorage-independent growth assay. Error bars represent the mean \pm SD values of three independent experiments $\left({ }^{*} P<0.05\right)$. e Luciferase reporter assays to determine GLI1 activity in indicated cells when treated with purmorphamine or not. Error bars represent the mean \pm SD values of three independent experiments $(* P<0.05)$

of GLI1- and GLI2-mediated transcription at the nuclear level-the colony formation ability of the cells was decreased (Fig. 6b). Furthermore, NUSAP1-siGLI1 significantly inhibited the cell invasion ability of SW 1088 cells, while treatment of the NUSAP1-transduced cells with GANT61 caused a greater decrease in their cell invasion ability (Fig. 6c). Moreover, NUSAP1-siGLI1 cells showed a decrease in their anchorage-independent growth ability, and treatment of the NUSAP1transduced cells with GANT61 also caused a significant decrease in their growth ability (Fig. 6d). Moreover, we found that, in response to SMO agonist purmorphamine treatment, the activity of GLI1 was only slightly increased in SW 1088 glioma cells, which displays low NUSAP1 expression, but significantly increased in U-87 MG glioma cells, which exhibits high NUSAP1 expression. Importantly, the simulative effect of SMO agonist purmorphamine on GLI1 activity in U-87 MG glioma cells was dramatically arrogated by NUSAP1 depletion (Fig. 6e). Therefore, these results further supported the notion that NUSAP1 plays critical role in activation of the Hedgehog signaling pathway in glioma cells.

\section{Discussion}

This study revealed that NUSAP1 plays a significant role in promoting aggressiveness in astrocytoma. We found that NUSAP1 expression was significantly upregulated in astrocytoma cell lines and tissues compared with normal astrocytes and brain tissues. We also found that overexpression of NUSAP1 was significantly correlated to poor survival. Moreover, NUSAP1 promoted the invasive ability of astrocytoma cells both under in vitro and in vivo conditions. With regard to the molecular mechanism, we found that upregulation of NUSAP1 promoted the translocation of GLI1 from the cytoplasm to the nucleus and upregulated the downstream genes of the $\mathrm{HH}$ pathway in astrocytoma cells. Taken together, our findings provided evidence for the role of NUSAP1 in the progression of astrocytoma and the potential of NUSAP1 as a prognostic biomarker as well as target in astrocytoma treatment.

The involvement of NUSAP1 in cancer has been reported in many studies. For instance, the expression level of NUSAP1 was strongly associated with poor survival in estrogen receptor-positive breast cancer [43]. Further, NUSAP1 could be a biomarker of oral squamous cell carcinoma, as it was reported that downregulation of NUSAP1 suppressed tumor proliferation and enhanced the anti-tumor effect of paclitaxel [44]. Moreover, NUSAP1 promoted prostate cancer progression by increasing the proliferation and invasion of prostate cancer cells [45]. NUSAP1 expression was also found to be 
upregulated in $95 \%$ of human pituitary gonadotroph adenomas [46]. Similar to the findings in benign brain tumor, NUSAP1 was reported to be overexpressed in grade III versus grade I meningiomas [47], and in glioblastoma multiforme [48]. Similar to these findings in various tumors, in this study too, we found that NUSAP1 was dramatically overexpressed in advanced stage astrocytoma patients; moreover, overexpression of NUSAP1 was also predictive of poor overall survival.

There is much evidence to indicate that $\mathrm{HH}$ signaling is involved in various cancers, including skin, muscle, esophagus, stomach, pancreas, biliary track, lung, prostate, bladder, oral cavity and brain cancer [49]. HH signaling was found to regulate dorsal brain tumorigenesis, and GLI1 expression was amplified by more than 50fold in malignant glioma [50, 51]. In agreement with these studies, in our study, we found that GLI1 expression in nucleus was upregulated by NUSAP1. NUSAP1 also upregulated the expression of the downstream targets of HH pathway including PTCH1, HIP1, CCND1, CCNE1 and HDAC1 in astrocytoma. Our findings indicated that NUSAP1 activated HH pathway by promoting GLI1 transport to the nucleus form cytoplasm in astrocytoma cell. GLI1, as a transcription factor, is a vital target gene of $\mathrm{HH}$ signaling, and it encodes for the $\mathrm{HH}$ signaling interacting protein [52]. However, while GLI1 mRNA expression level was widely known to reflect the activity of the HH signaling pathway [53], GLI1 was also regulated by several protein mediators, such as protein kinase $\mathrm{A}$, glycogen synthase kinase $3 \beta$, casein kinase $1 \alpha$ and suppressor of fused [54]. Peterson KA et al. defined a prioritized set of 841 enriched Gli1-binding regions (GBRs) by intersecting ChIP combined with deep sequencing (ChIP-seq) data independently verified in biological replicates [42]. NUSAP1 as one of the genes which have GLI-binding regions, however, has not been validated by any experiments as far as we known. Hence, there are more studies will be needed to testify whether NUSAP1 directly binding to GLI1. Here, we reported that NUSAP1 could promote GLI1 translocation to the cell nucleus, resulting in the activation of $\mathrm{HH}$. However, we could not obtain any direct evidence to precisely show how NUSAP1 promotes GLI1 translocation to the nucleus. Therefore, this is a topic that needs to be studied further in the future.

In conclusion, our study revealed that NUSAP1 plays an important role in astrocytoma progression by promoting the proliferation, invasion and migration of tumor cells. Furthermore, the level of NUSAP1 was notably positively related to poor overall survival in astrocytoma patients. Thus, NUSAP1 might be a potential prognostic biomarker as well as a treatment target in astrocytoma. With regard to the underlying mechanism, NUSAP1 could promote GLI1 translocation to the nucleus and thereby result in the activation of the $\mathrm{HH}$ signaling pathway. However, the precise molecular mechanism by which NUSAP1 promotes the nuclear translocation of GLI1 is still unclear and needs to be explored in future studies.

\section{Conclusion}

NUSAP1 contributes to the progression of astrocytoma by enhancing tumor cell invasiveness via activation of the Hedgehog signaling pathway, and that NUSAP1 might be a potential prognostic biomarker as well as a target in astrocytoma.

\section{Additional files}

Additional file 1: Table S1. Clinicopathological characteristics of studied patients and expression of NUSAP1 in 221 glioma specimens. Table S2. Correlation between NUSAP1 expression and clinicopathological characteristics of 221 glioma specimens. Table S3. Univariate and multivariate analyses of various prognostic parameters in patients with glioma by Coxregression analysis (DOCX $21 \mathrm{~kb}$ )

Additional file 2: Figure S1. NUSAP1 expression is negatively correlated with prognosis in both patients with lower- and higher- grade gliomas. Kaplan-Meier survival curves of patients with lower-grade glioma (grade I-II, $P<0.001$, left) and with higher-grade glioma (grade III-IV, $P=0.018$, right). (TIFF $80 \mathrm{~kb}$ )

Additional file 3: Figure S2. Upregulation of NUSAP1 promoted the aggressiveness in astrocytoma in vitro. (A) Western blotting was used to examine the protein expression of NUSAP1 in A172 cells. a-Tubulin was used as a loading control. (B) In the MTT assay, overexpression of NUSAP1 significantly increased the growth rate of the indicated cells, while downregulation of NUSAP1 decreased the growth rate of the indicated cells. Error bars represent the mean \pm SD values of three independent experiments. (C) Representative images (left panel) and quantification (right panel) of cells in the colony formation assay. Overexpression of NUSAP1 increased, while downregulation of NUSAP1 decreased, the colony-forming ability of the indicated cells. Error bars represent the mean \pm SD values of three independent experiments $\left({ }^{*} P<0.05\right)$. (D) Representative images (left panel) and quantification (right panel) of the indicated invaded cells analyzed by the Transwell matrix penetration assay. Error bars represent the mean \pm SD values of three independent experiments ( $\left.{ }^{*} P<0.05\right)$. (E) The wound-healing assay was conducted with the indicated cells, and images were taken at 0 and $24 \mathrm{~h}$. Overexpression of NUSAP1 increased, while downregulation of NUSAP1 decreased, the migration ability of the indicated cells. (F) Representative images (left panel) and quantification (right panel) of the indicated invaded cells by the anchorage-independent growth assay. Error bars represent the mean \pm SD values of three independent experiments $\left({ }^{*} P<0.05\right)$. (G) Western blotting was used to assess the expression of NUSAP1, MMP2, MMP9 and Ki67 in the indicated cells. GAPDH was used as a loading control. (TIFF $13300 \mathrm{~kb}$ )

Additional file 4: Figure S3. Upregulation of NUSAP1 activated Hedgehog signaling. (A) Western blotting was used to examine the expression of NUSAP1 and GLI1 in the indicated cells. $\beta$-actin and EF1-a were used as loading controls. (B) Relative activity of reporter luciferase linked to NUSAP1 and GLI1 in the indicated cells. Error bars represent the mean \pm SD values of three independent experiments $\left({ }^{*} P<0.05\right)$. (CD) RT-PCR detection of PTCH1, HIP1, CCND1, CCNE1 and HDAC1 gene expression in A172 cells. Error bars represent the mean \pm SD values of three independent experiments $\left({ }^{*} P<0.05\right)$. (TIFF $\left.1234 \mathrm{~kb}\right)$

\section{Abbreviations}

AJCC: American joint committee on cancer; ATCC: American type culture collection; DHH: Desert hedgehog; DMEM: Dulbecco's modified eagle medium; EF1a: Elongation factor 1 alpha; FBS: fetal bovine serum; 
GAPDH: Glyceraldehyde-3-phosphate dehydrogenase; GLI1: GLI family zinc finger 1; GSEA: Gene set enrichment analysis; H\&E: Hematoxylin-eosin; HH: Hedgehog; IHH: Indian hedgehog; MOD: Mean optical density; MTT: 3(4,5-dimethylthiazol-2-yl) 2,5-diphenyltetrazolium bromide; NHAs: Primary normal human astrocytes; NUSAP1: Nucleolar and spindle associated protein 1; RFS: Relapse-free survival; SD: Standard deviation; SHH: Sonic hedgehog; SI: Staining index; SMO: Smoothened; WHO: World health organization

\section{Acknowledgements}

Not applicable.

\section{Funding}

This work was supported by the Ministry of Science and Technology of China grant (973 Program, No. 2014CB91060); and the Natural Science Foundation of China (No. 81773106, 81,325,013, 81,530,082, 91,529,301, $81,672,874$ and 81,621,004); the Science and Technology of Guangdong Province (No.2016A030308002, 2015A030313468, 2014A030313008 and 2014A030313220); the Distinguished Young Scholar of Guangdong Province, China (No. 2015A030306033); the Innovative Academic Team of Guangzhou Education System (No. 1201610014); Guangdong science and technology innovation young top-notch talent (No. 2016TQ03R801); the Guangzhou scholars research projects of Guangzhou municipal colleges and universities (No. 12A009D).

\section{Availability of data and materials}

The datasets generated and analyzed during the current study are available in TCGA (http://cancergenome.nih.gov/).

\section{Authors' contributions}

$X W, B X$ and $C Y$ carried out most of the experimental work; $W W$ and DZ conducted the molecular cloning and animal experiments; ZZ and LH conducted the IHC analysis; YH, $\sqcup$ and $J \mathrm{~L}$ analyzed the data; $L S$ and $W Z$ supervised the project and wrote the manuscript. All authors read and approved the final manuscript.

\section{Ethics approval and consent to participate}

This study was approved by the Ethical Committee of the Sun Yat-sen University-Affiliated First Hospital. Prior donor consent and the approval of the Institutional Research Ethics Committee from all patients were obtained for use of the data. Additionally, the animal study was approved by the Ethics Committee of Sun Yat-Sen University, and all the experiments conform to the relevant regulatory standards.

\section{Consent for publication}

Not applicable.

\section{Competing interests}

The authors declare that they have no competing interests.

\section{Publisher's Note}

Springer Nature remains neutral with regard to jurisdictional claims in published maps and institutional affiliations.

\footnotetext{
Author details

${ }^{1}$ State Key Laboratory of Oncology in Southern China and Department of Experimental Research, Sun Yat-sen University Cancer Center, Guangzhou 510060, China. ${ }^{2}$ Department of Anatomy, Medical School of Yangtzeu University, Guangzhou, China. ${ }^{3}$ Department of Neurosurgery, First Affiliated Hospital of Sun Yat-sen University, Guangzhou, China. ${ }^{4}$ Neurosurgical Research Institute, the First Affiliated Hospital of Guangdong Pharmaceutics University, Guangzhou 510060, China. ${ }^{5}$ Key Laboratory of Protein Modification and Degradation, School of Basic Medical Sciences, Affiliated Cancer Hospital \& Institute of Guangzhou Medical University, Guangzhou Medical University, Guangzhou, China. ${ }^{6}$ Guangdong Province Key Laboratory of Brain Function and Disease, Department of Biochemistry, Zhongshan School of Medicine, Sun Yat-sen University, Guangzhou, China.
}

Received: 15 June 2017 Accepted: 6 September 2017 Published online: 12 September 2017

\section{References}

1. Stupp R, Mason WP, van den Bent MJ, et al. Radiotherapy plus concomitant and adjuvant temozolomide for glioblastoma. N Engl J Med. 2005;352:987-96.

2. Brada M, Stenning S, Gabe R, et al. Temozolomide versus procarbazine, lomustine, and vincristine in recurrent high-grade glioma. J Clin Oncol. 2010;28:4601-8.

3. Morris PG, Lassman AB. Medical oncology: optimizing chemotherapy and radiotherapy for anaplastic glioma. Nat Rev Clin Oncol. 2010;7:428-30.

4. Curran WJ Jr, Scott CB, Horton J, et al. Recursive partitioning analysis of prognostic factors in three radiation therapy oncology group malignant glioma trials. J Natl Cancer Inst. 1993;85:704-10.

5. Grossman SA, Ye X, Piantadosi S, et al. Survival of patients with newly diagnosed glioblastoma treated with radiation and temozolomide in research studies in the United States. Clin Cancer Res. 2010;16:2443-9.

6. Butowski NA, Sneed PK, Chang SM. Diagnosis and treatment of recurrent high-grade astrocytoma. J Clin Oncol. 2006;24:1273-80.

7. Komotar RJ, Mocco J, Jones JE, et al. Pilomyxoid astrocytoma: diagnosis, prognosis, and management. Neurosurg Focus. 2005;18:E7.

8. See SJ, Gilbert MR. Anaplastic astrocytoma: diagnosis, prognosis, and management. Semin Oncol. 2004;31:618-34.

9. Louis DN, Ohgaki H, Wiestler OD, et al. The 2007 WHO classification of tumours of the central nervous system. Acta Neuropathol. 2007;114:97-109.

10. Ostrom QT, Gittleman H, Fulop J, et al. CBTRUS statistical report: primary brain and central nervous system tumors diagnosed in the United States in 2008-2012. Neuro-Oncology. 2015;17:iv1-iv62.

11. Nusslein-Volhard C, Wieschaus E. Mutations affecting segment number and polarity in drosophila. Nature. 1980;287:795-801.

12. Xie K, Abbruzzese JL. Developmental biology informs cancer: the emerging role of the hedgehog signaling pathway in upper gastrointestinal cancers. Cancer Cell. 2003;4:245-7.

13. Ng JM, Curran T. The Hedgehog's tale: developing strategies for targeting cancer. Nat Rev Cancer. 2011;11:493-501.

14. Finco I, LaPensee CR, Krill KT, et al. Hedgehog signaling and steroidogenesis. Annu Rev Physiol. 2015;77:105-29.

15. Dahmane N, Lee J, Robins $P$, et al. Activation of the transcription factor Gli1 and the sonic hedgehog signalling pathway in skin tumours. Nature. 1997;389:876-81.

16. Athar M, Li C, Tang X, et al. Inhibition of smoothened signaling prevents ultraviolet B-induced basal cell carcinomas through regulation of Fas expression and apoptosis. Cancer Res. 2004;64:7545-52.

17. Watkins DN, Berman DM, Burkholder SG, et al. Hedgehog signalling within airway epithelial progenitors and in small-cell lung cancer. Nature. 2003:422:313-7.

18. Sanchez P, Hernandez AM, Stecca B, et al. Inhibition of prostate cancer proliferation by interference with SONIC HEDGEHOG-GLI1 signaling. Proc Natl Acad Sci U S A. 2004;101:12561-6.

19. Berman DM, Karhadkar SS, Maitra A, et al. Widespread requirement for hedgehog ligand stimulation in growth of digestive tract tumours. Nature. 2003:425:846-51.

20. Ma X, Sheng T, Zhang $Y$, et al. Hedgehog signaling is activated in subsets of esophageal cancers. Int J Cancer. 2006;118:139-48.

21. Thayer SP, di Magliano MP, Heiser PW, et al. Hedgehog is an early and late mediator of pancreatic cancer tumorigenesis. Nature. 2003;425:851-6.

22. Cheng WT, Xu K, Tian DY, et al. Role of hedgehog signaling pathway in proliferation and invasiveness of hepatocellular carcinoma cells. Int J Oncol. 2009;34:829-36.

23. Tada M, Kanai F, Tanaka Y, et al. Down-regulation of hedgehog-interacting protein through genetic and epigenetic alterations in human hepatocellular carcinoma. Clin Cancer Res. 2008;14:3768-76.

24. Thompson MC, Fuller C, Hogg TL, et al. Genomics identifies medulloblastoma subgroups that are enriched for specific genetic alterations. J Clin Oncol. 2006:24:1924-31.

25. Kool M, Koster J, Bunt J, et al. Integrated genomics identifies five medulloblastoma subtypes with distinct genetic profiles, pathway signatures and clinicopathological features. PLoS One. 2008;3:e3088.

26. Northcott PA, Nakahara Y, Wu X, et al. Multiple recurrent genetic events converge on control of histone lysine methylation in medulloblastoma. Nat Genet. 2009;41:465-72. 
27. Ehtesham M, Sarangi A, Valadez JG, et al. Ligand-dependent activation of the hedgehog pathway in glioma progenitor cells. Oncogene. 2007;26:5752-61

28. Becher OJ, Hambardzumyan D, Fomchenko El, et al. Gli activity correlates with tumor grade in platelet-derived growth factor-induced gliomas. Cancer Res. 2008;68:2241-9.

29. Cui $D, X u$ Q, Wang K, et al. Gli1 Is a potential target for alleviating multidrug resistance of gliomas. J Neurol Sci. 2010;288:156-66.

30. Wang K, Pan L, Che X, et al. Sonic hedgehog/GLI(1) signaling pathway inhibition restricts cell migration and invasion in human gliomas. Neurol Res. 2010;32:975-80.

31. Raemaekers T, Ribbeck K, Beaudouin J, et al. NuSAP, a novel microtubuleassociated protein involved in mitotic spindle organization. J Cell Biol. 2003;162:1017-29.

32. Hussain S, Benavente SB, Nascimento E, et al. The nucleolar RNA methyltransferase Misu (NSun2) is required for mitotic spindle stability. J Cell Biol. 2009;186:27-40.

33. Ribbeck K, Groen AC, Santarella R, et al. NuSAP, a mitotic RanGTP target that stabilizes and cross-links microtubules. Mol Biol Cell. 2006;17:2646-60.

34. Ribbeck K, Raemaekers T, Carmeliet G, et al. A role for NuSAP in linking microtubules to mitotic chromosomes. Curr Biol. 2007;17:230-6.

35. Kokkinakis DM, Liu X, Neuner RD. Modulation of cell cycle and gene expression in pancreatic tumor cell lines by methionine deprivation (methionine stress): implications to the therapy of pancreatic adenocarcinoma. Mol Cancer Ther. 2005;4:1338-48.

36. Wadia PP, Coram M, Armstrong RJ, et al. Antibodies specifically target AML antigen NuSAP1 after allogeneic bone marrow transplantation. Blood. 2010;115:2077-87.

37. Iyer J, Moghe S, Furukawa M, et al. What's Nu(SAP) in mitosis and cancer? Cell Signal. 2011;23:991-8.

38. Gulzar ZG, McKenney JK, Brooks JD. Increased expression of NuSAP in recurrent prostate cancer is mediated by E2F1. Oncogene. 2013;32:70-7.

39. Lee J, Kotliarova $S$, Kotliarov $Y$, et al. Tumor stem cells derived from glioblastomas cultured in bFGF and EGF more closely mirror the phenotype and genotype of primary tumors than do serum-cultured cell lines. Cancer Cell. 2006;9:391-403.

40. Zeng Z, Lin H, Zhao X, et al. Overexpression of GOLPH3 promotes proliferation and tumorigenicity in breast cancer via suppression of the FOXO1 transcription factor. Clin Cancer Res. 2012;18:4059-69.

41. Li J, Zhang N, Song LB, et al. Astrocyte elevated gene-1 is a novel prognostic marker for breast cancer progression and overall patient survival. Clin Cancer Res. 2008;14:3319-26.

42. Peterson KA, Nishi Y, Ma W, et al. Neural-specific Sox2 input and differential Gli-binding affinity provide context and positional information in Shhdirected neural patterning. Genes Dev. 2012;26:2802-16.

43. Liu R, Guo CX, Zhou HH. Network-based approach to identify prognostic biomarkers for estrogen receptor-positive breast cancer treatment with tamoxifen. Cancer Biol Ther. 2015;16:317-24.

44. Okamoto A, Higo M, Shiiba M, et al. Down-regulation of Nucleolar and spindle-associated protein 1 (NUSAP1) expression suppresses tumor and cell proliferation and enhances anti-tumor effect of Paclitaxel in oral Squamous cell carcinoma. PLoS One. 2015;10:e0142252.

45. Gordon CA, Gulzar ZG, Brooks JD. NUSAP1 Expression is upregulated by loss of RB1 in prostate cancer cells. Prostate. 2015:75:517-26.

46. Lee M, Marinoni I, Irmler M, et al. Transcriptome analysis of MENX-associated rat pituitary adenomas identifies novel molecular mechanisms involved in the pathogenesis of human pituitary gonadotroph adenomas. Acta Neuropathol. 2013;126:137-50.

47. Stuart JE, Lusis EA, Scheck AC, et al. Identification of gene markers associated with aggressive meningioma by filtering across multiple sets of gene expression arrays. J Neuropathol Exp Neurol. 2011;70:1-12.

48. Marie SK, Okamoto OK, Uno M, et al. Maternal embryonic leucine zipper kinase transcript abundance correlates with malignancy grade in human astrocytomas. Int J Cancer. 2008;122:807-15.

49. Beachy PA, Karhadkar SS, Berman DM. Tissue repair and stem cell renewal in carcinogenesis. Nature. 2004:432:324-31.

50. Dahmane N, Sanchez P, Gitton Y, et al. The sonic hedgehog-Gli pathway regulates dorsal brain growth and tumorigenesis. Development. 2001;128:5201-12

51. Kinzler KW, Bigner SH, Bigner DD, et al. Identification of an amplified, highly expressed gene in a human glioma. Science. 1987;236:70-3.
52. Ingham PW, McMahon AP. Hedgehog signaling in animal development: paradigms and principles. Genes Dev. 2001;15:3059-87.

53. Scales SJ, de Sauvage FJ. Mechanisms of hedgehog pathway activation in cancer and implications for therapy. Trends Pharmacol Sci. 2009:30:303-12.

54. Merchant M, Vajdos FF, Ultsch M, et al. Suppressor of fused regulates Gli activity through a dual binding mechanism. Mol Cell Biol. 2004:24:8627-41.

\section{Submit your next manuscript to BioMed Central and we will help you at every step:}

- We accept pre-submission inquiries

- Our selector tool helps you to find the most relevant journal

- We provide round the clock customer support

- Convenient online submission

- Thorough peer review

- Inclusion in PubMed and all major indexing services

- Maximum visibility for your research

Submit your manuscript at www.biomedcentral.com/submit
) Biomed Central 